\title{
Mac Cheever (1944-2021): a tribute to a life of achievement and service
}

\author{
Philip D Greenberg (D) , ${ }^{1,2}$ Mary L Disis (D) ," Kim A Margolin (D) , \\ Lynn M Matrisian (D) , ${ }^{5}$ Paul M Sondel (D) ${ }^{6}$
}

To cite: Greenberg PD, Disis ML, Margolin KA, et al. Mac Cheever (1944-2021): a tribute to a life of achievement and service. Journal for ImmunoTherapy of Cancer 2022;10:e004433. doi:10.1136/ jitc-2021-004433

Accepted 23 December 2021

Check for updates

(C) Author(s) (or their employer(s)) 2022. Re-use permitted under CC BY-NC. No commercial re-use. See rights and permissions. Published by BMJ.

${ }^{1}$ Program in Immunology, Fred Hutchinson Cancer Research Center, Seattle, Washington, USA ${ }^{2}$ Medicine and Immunology, University of Washington, Seattle, WA, USA

${ }^{3}$ Tumor Vaccine Group, Center for Translational Medicine in Women's Health, University of Washington, Seattle,

Washington, USA

${ }^{4}$ Melanoma Program, St John's Cancer Institute, Santa Monica, California, USA

${ }^{5}$ Pancreatic Cancer Action Network, Manhattan Beach, California, USA

${ }^{6}$ Pediatrics, Human Oncology, and Genetics, and Carbone Cancer Center, University of Wisconsin-Madison, Madison, Wisconsin, USA

Correspondence to Dr Philip D Greenberg pgreen@uw.edu
Mac Cheever left this world way too soon on September 23, 2021, and, while he will be greatly missed both personally and professionally, his contributions and imprint, especially in the field of immunotherapy of cancer, will certainly be enduring. He was also a devoted and loving friend, husband, and father, who had a passion for the outdoors, biking, boating, and traveling, and had a delightfully dry sense of humor that could be counted on to make you smile and lighten your load. Mac always fashioned himself as being a translational immuno-oncologist, even from a time when most questioned if immuno-oncology would ever be a legitimate discipline and there was little evidence that there were reagents or strategies to translate. He spent his academic life making that moniker more than a respectable reality, and was instrumental in developing, promoting, and nurturing the field from its uncertain beginnings into the impactful therapeutic strategy it is today. He was kind, generous, and humorous as a friend; modest, insightful, honest, and visionary as a colleague; and knowledgeable, candid, and supportive as a mentor. It is unfortunate that he will not get to see all the fruits of his labors mature, but he has departed knowing that, due in no small part to his efforts, immunotherapy is becoming established as a pillar of cancer treatment and having an ever-increasing beneficial impact on the quality of life and treatment outcome of patients with cancer.

Mac grew up in Allegan, Michigan, a small town in Western Michigan with a population of less than 5000, which no doubt imbued him with the classic midwestern traits and sensibilities that so well describe him: friendly, modest, helpful, and family- oriented. He went to the University of Michigan undergraduate and medical schools, receiving his MD degree in 1970. During his senior year in medical school, he did an externship in Uganda, and the resulting experiences with John Ziegler, most especially seeing the incredibly dramatic responses to cyclophosphamide being observed for the first time in patients with Burkitt's lymphoma, which he described as watching 'the tumors just melt away', greatly influenced his subsequent career choices. Thus, after completing medical residency at the University of Washington (UW), he embarked on an Oncology fellowship. At that time, the Oncology Division at the UW, under the directorship of eventual Nobel Laureate E. Donnall Thomas, was first demonstrating that allogeneic hematopoietic cell transplantation (HCT) could be an effective treatment for refractory leukemias, and that a major reason for the therapeutic benefit observed in some patients was an immune antileukemic response mediated by donor $\mathrm{T}$ cells transferred to the patient with other hematopoietic cells.

Mac was intrigued and became clinically involved in these early and ultimately highly successful efforts to develop HCT as a treatment modality, but what really caught his interest was the therapeutic $\mathrm{T}$ cell response responsible for most of the benefit of HCT, the graft versus leukemia effect, and the associated problem of significant toxicity from concurrent $\mathrm{T}$ cell recognition of normal host tissues because there was no selection for the specificity of the infused T cells. He realized the importance of defining the immunogenic tumor targets that could be recognized and the potential benefit of infusing only $\mathrm{T}$ cells specific for such targets, and thus decided to complete his training by joining Alex Fefer's then relatively young and

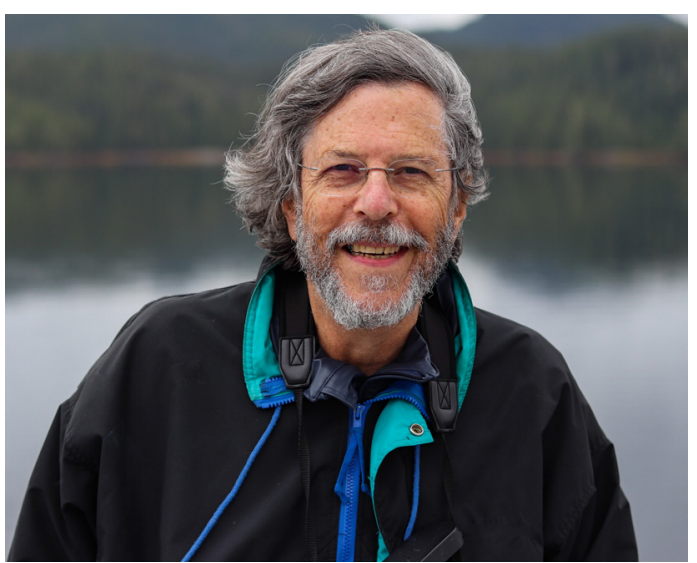


small lab group that was pursuing in mouse models the entirely novel strategy of adoptive T cell therapy with tumorspecific T cells. Two years later, Phil Greenberg also joined the group, and that began a very collaborative, productive 15-year period in which they defined many of the basic principles underlying antigen-specific $\mathrm{T}$ cell therapy and what would be required to translate those findings from the lab to the clinic. Mac was intensely focused on the work being translational, and made many seminal discoveries during this time that were not only foundational for the fields of cancer immunotherapy and adoptive cellular therapy, and which we now take for granted, but were also essential for taking that difficult step to move something from the lab to the clinic, including: (1) tumor-reactive T cells could be generated and expanded in vitro; (2) such ex vivo expanded cancer-specific $T$ cells could, once generated to sufficient numbers, mediate cancer therapy following transfer in vivo; (3) antitumor efficacy and in vivo T cell proliferation could be enhanced with retention of specificity by administration post-transfer of low doses of $\mathrm{T}$ cell growth factors (IL-2); and (4) T cell survival and therapeutic activity could be increased by prior immunosuppressive and lympholytic chemotherapy - the prelude to the now standard lymphodepletion strategy.

By the end of the 1980s, the Rosenberg group at the National Cancer Institute (NCI) had begun demonstrating that transfer of patient lymphocytes non-specifically expanded in vitro could mediate therapeutic effects, but there was limited evidence of selective tumor-reactivity and still significant toxicity. Consequently, Mac made the decision to change the direction of his lab to focus on identifying antigens expressed by tumors that could serve as specific targets. He was one of the earliest scientists to investigate specific targeting of oncogenic proteins with $\mathrm{T}$ cells, and began working on mutated Ras, Bcr-abl, HER2/neu and WT1. With the preclinical validation of several of these proteins as targets, and with the technologies for specific $\mathrm{T}$ cell therapy still not developed, he rapidly moved from the preclinical results to therapeutic vaccines, including initiating human trials with HER2/neu vaccines in collaboration with Nora Disis, a trainee from his lab, and one of his many professional 'children' of whom he was most proud. The potential of this work was broadly recognized, and he was awarded two consecutive MERIT Awards from the NCI to help advance this effort.

However, the field was moving too slowly for Mac, and in 1994 he cofounded, with his close friend Olja Finn and other colleagues, and then joined and helped lead the biotech company Corixa with the goals of identifying immunogenic tumor antigens and creating therapeutic cancer vaccines. Several vaccines were advanced into clinical trials, but it rapidly became evident that therapeutic vaccines to enhance $\mathrm{T}$ cell responses suffered from poor immunogenicity in cancer patients, a problem the field has still not been able to adequately solve. To improve the vaccine responses, Corixa developed as an adjuvant a tolllike receptor agonist, monophosphoryl lipid A, which has become an essential component of the approved preventive
HPV vaccine, Cervarix. Such adjuvants represented a significant step forward, but there remained much to be learnt to realize the potential of cancer vaccines. However, while pursuing this work, in 2005 Corixa was fully acquired by GlaxoSmithKline, and Mac returned to the UW/Fred Hutchinson Cancer Research Center as the Director of Solid Tumor Research, with the goal of enhancing and increasing the breadth of the clinical research program.

Concurrently, cancer immunotherapy was starting to come of age, and Mac was recruited by the American Association of Immunologists and American Association of Cancer Research to lead an Extramural Immunology Expert Steering Committee and serve as Committee liaison to the NCI. The mandate for the committee was an unavoidable attraction for him, namely to help the NCI resolve the question: 'Why is it that basic scientists have invented so many immunotherapy agents that could benefit patients and yet so few are being tested in patients?' The NCI expanded his committee advisory role by also hiring him in 2006 to function as a half-time consultant for immunotherapy, and Mac selflessly dedicated the next 2 years of his life living and working on two coasts, with his weeks working in Bethesda dedicated to finding ways to speed the advance of the field of immunotherapy. The committee concluded that one solvable core problem was a lack of focus and prioritization by the cancer research enterprise, and Mac set out to fix that. He organized the NCI-sponsored Immunotherapy Agent Workshop in 2007 to develop a ranked list of 20 high priority agents that, if made available to the cancer research community, could benefit cancer patients. The Workshop was broadly inclusive of members of academia, industry, the NCI, and the Food and Drug Administration, and the resultant recommended list was used to justify the development of the agents to company executives and funders and the distribution to clinical researchers for studies in patients. The priority list was prophetic, as it included what we now think of as the usual suspects, and for example had antiPD1 placed second on the list despite the absence at that time of clinical data supporting its use. This effort helped hasten translational studies with immunologic reagents, a goal always close to Mac's heart.

The committee next tackled the problem of selecting immunologic cancer targets, and in 2008 initiated the Cancer Antigen Pilot Prioritization Project to develop objective criteria for optimal cancer vaccines and then rank the top 75 known cancer antigens in clinical trials or preclinical development. The list became, and remains, a highly cited resource for the community, and the weighted objective criteria that were developed continue to be used by academic and industry scientists to assess the relative worth of known and newly discovered cancer antigens. Most importantly, this again created the foundation for translational studies that could increase the likelihood of therapeutic success.

For a translational immuno-oncologist, there was still something missing - a structure that could support and actuate the recommendations of the committee. Thus, Mac, with the backing of the Committee, next successfully 
lobbied the NCI Director to fund a Cancer Immunotherapy Trials Network (CITN) to provide the resources and infrastructure needed to help develop the reagents. Convincing the NCI to create the CITN was in itself remarkable as it came not only at a time of national fiscal restraint but also before the approval of CTLA- 4 blockade therapy, when many in cancer research still greatly questioned not just the present but the future of immunotherapy as a cancer treatment modality. Establishing an NCI-sponsored program to validate and push the field was a critical element to bringing immunotherapy into the mainstream.

Mac submitted a proposal to the National Institutes of Health that represented his vision for leading and directing the CITN, and was awarded a competitive grant in 2010 to head the original CITN Central Operations and Statistical Center at the Fred Hutch, and he continued as head from its inception. His operative concept for the CITN was inclusivity, and the initial network included investigators from 28 institutions (now expanded to nearly twice that number) who were similarly committed to collaborate, design, implement, and conduct early phase trials using high priority immunologic reagents and to generate high quality immunological and biomarker data that could elucidate mechanisms of response and obstacles to success. Getting the grant was a great stride forward, but making the CITN successful, despite being very under-funded for the lofty goals, was a more difficult step as it required buy-in not just from the academic participants but from biotech and pharma partners who had made or were making the reagents. Mac was the ideal person to make this happen, using his experience in the biotech industry, links with decision makers in pharma, familiarity with the NCI structure, and his gentle and affable but very persuasive manner to get people to recognize that all, and especially patients, would benefit from a unified collaborative effort and that reagents that really worked would be recognized and could be fasttracked toward approval.

The list of drugs that have been tested and advanced through CITN-supported trials and the CITN network is long and includes the impactful reagents that the advisory committee highlighted. The reagents target distinct aspects of an effective immune response, including reagents targeting dendritic cells such as anti-CD40 and Flt3-Ligand, immune activators such as IFN $\gamma$ and the adjuvant polyIC-LC, $\mathrm{T}$ cell stimulators and expanders such as IL-15 and IL-7, checkpoint inhibitors such as anti-PD-1/ PD-L1, and tumor microenvironment modulators such as IDO inhibitors; and many of these have now been approved or are on a path to approval. Mac was very encouraged by this progress but was particularly proud of making sure that patients with less common diseases and pediatric patients were also included in trials even though they might otherwise be excluded because they represented a potentially less profitable market share for commercial partners. For example, CITN-supported trials with Paul Nghiem evaluating anti-PDL1 in patients with Merkel Cell Carcinoma led to dramatic responses and benefit to patients, leading to approval of the drug for this specific orphan indication.

Mac received much recognition and numerous awards during his career, but perhaps none meant more than being the first recipient of the Society for Immunotherapy of Cancer (SITC) Distinguished Service Award, as his personal career mission was essentially identical to the mission of SITC: 'improving cancer patient outcomes by advancing the science, development, and application of cancer immunology and immunotherapy through the core values of interaction/integration, innovation, translation, and leadership'. He spent much of his career elevating the visibility of the field of immunooncology and making it one that could attract the full breadth of basic, translational, and clinical scientists. He had a passion for teaching, was committed to developing the next generation of immuno-oncologists, and tried to make certain that his trainees acquired the tools needed to succeed in science. He made certain that the resources of the GITN were used in part to recruit and support young investigators, and he gladly assumed the role of nurturing their careers. In accepting the SITC award, Mac must have felt particularly gratified when, after looking over the audience, he said: 'The best thing about this award ceremony is seeing all the younger scientists who are poised to take over for us, and it is very clear that the field is in good stead'. Mac was an original-existing and future immuno-oncologists, as well as patients, will forever be indebted for all that he did to establish the scientific foundation for the field of cancer immunotherapy, expand its horizons, and create an infrastructure that welcomes new investigators and supports translation to the clinic. He will be greatly missed by his many friends and the great number of people whose lives he touched and benefited, and by his loving and devoted family, especially his wife Linda and two sons Alex and Paul, who were always at his side and in his thoughts. As the philosopher William James stated, 'the great use of a life is to spend it for something that will outlast it', and Mac most certainly lived that life.

Funding The authors have not declared a specific grant for this research from any funding agency in the public, commercial or not-for-profit sectors.

Competing interests None declared.

Patient consent for publication Consent obtained directly from patient(s)

Provenance and peer review Commissioned; internally peer reviewed.

Open access This is an open access article distributed in accordance with the Creative Commons Attribution Non Commercial (CC BY-NC 4.0) license, which permits others to distribute, remix, adapt, build upon this work non-commercially, and license their derivative works on different terms, provided the original work is properly cited, appropriate credit is given, any changes made indicated, and the use is non-commercial. See http://creativecommons.org/licenses/by-nc/4.0/.

\section{ORCID iDs}

Philip D Greenberg http://orcid.org/0000-0003-3812-647X Mary L Disis http://orcid.org/0000-0001-7653-4648

Kim A Margolin http://orcid.org/0000-0002-5248-4356

Lynn M Matrisian http://orcid.org/0000-0002-5631-2826

Paul M Sondel http://orcid.org/0000-0002-0981-8875 